\title{
Information Communication Technology Influence on E- Payment Adoption: A Point of View of Banking Institutions in Jordan
}

\author{
Naim S. Al-Qadi, PhD \\ Associate Professor \\ Department of Finance \\ Albalqa Applied University
}

\begin{abstract}
Banks have to adopt new information and communication technologies such as e-banking and e-payments to maintain competitive positioning. The purpose of this quantitative correlational research is to determine if a relationship exists between the variables of security, usability and support and epayment adoption in the banking system in Jordan. The Unified Theory of Acceptance and Use of Technology (UTAUT) provided the conceptual framework for the study. The hypothesis tested by the study stated in its alternative form was: A statistically significant relationship exists between Security, Usability, and Support and E-Payment Adoption. Data were collected using a survey instrument designed for the study through random sampling of managers and employees at banking institutions in Jordan. The results of the analysis of data show that the predictor variables of Security, Usability, and Support have a statistically significant relationship with the outcome variable of E-Payment Adoption. While each of the three predictor variables had a statistically significant relationship with the outcome variable of E-Payment Adoption, the strongest relationship was with the users' perception of Support. The implication of the results is that banks in Jordan should focus on the three predictor variables to obtain competitive advantages through user adoption of e-payments.
\end{abstract}

\section{Keywords}

UTAUT, Security, Usability, Support, E-Payment

\section{INTRODUCTION}

The success of companies in the banking industry is often linked to the ability to innovate, which includes adopting new information communication technologies (ICT). Banks have to adopt new technologies such as e-banking and e-payments to maintain competitive positioning in a market [1].The purpose of this quantitative correlational research is to determine if a relationship exists between the variables of security, usability and support and e-payment adoption in the banking system in Jordan.

For the purposes of this research, the variable of security is defined as perceived safety of a system from unauthorized access and use [2]. The definition of usability is a bundle of attributes that includes perceptions the system is easy to learn, efficient to use, relatively error free, and subjectively pleasing [3]. Support refers to the degree an individual believes the organization and technical infrastructure supports the use of the technology [4]. E-payment is an online payment system using ICT for the transfer of money [5].

\section{LITERATURE REVIEW}

The literature review examined previous research related to the influence of security, usability, and support on the adoption of e-payments [6]; [7]. The characteristics of social media also affect the decision of an individual to use a technology such as e-payments. Consequently, many variables influence the decision to adopt e-payment technology.

\subsection{Characteristics of Social Media}

Research [8] investigated the characteristics of social media as perceived by users. Social media allows the users to generate content and to form virtual communities composed of individuals with similar interests. Social media also allows the rapid exchange of information, which includes perceptions of the utility, usability, and security associated with new technologies. Social media platforms vary significantly in the type of users they attract, which depends on the format of the platform.

\section{Security}

Previous research examining security in e-payment systems have focused on the methods used to verify the identity of individuals logging into an e-payment account. The most common method of authentication is a personal identification number, with some systems relying on digital signatures and biometrics [5]. Effective security measures by the bank or other organization hosting the e-payment platform have to include protections against attacks aimed at the system such as the insertion of a virus or worm into the e-payment system. Because the nature of security threats is constantly evolving the bank has to ensure it has state-of-the art security measures. The literature indicates that the most effective security measures include educating consumers about security practices, which also increases the confidence of the user in the security of the system [2]. Research suggests that educating consumers about e-payment security has the additional benefit of fostering positive attitudes towards the scope of security in the e-payment platform.

\section{Usability}

In a study collecting data from human resource professionals, [7] determined that a key factor in the adoption of an electronic human resources management (E-HRM) system was usability. The system quality and the information quality were the key factors in the intention to use the system among professionals. Research by [3], however, determined that usability is a subjective perception and depends on both the design of the ICT system and the characteristics of the individual user. The user of a system forms a perception of usability based on the total experience associated with using the system. An additional finding of the research was that individuals with experience with ICT systems are more likely 
to be satisfied with the usability of a system. In contrast, individuals with relatively little computer experience may find the same system as having low usability. In practice, the epayment platform must not only be well-designed, but also must contain features reflecting the way the majority of people actually use the system.

\section{Support}

A study by [9] found that the degree of support provided to the customer affects the perception of service quality in online transactions. In addition, an interrelationship exists between the perception of support and the perception of other attributes associated with an online platform such as security. Factors such as awareness of support and the ease of accessing support contribute to the overall perspective of the users of the adequacy of support in e-payment systems. In a study examining factors influencing adopt of new internet technologies among older adults, [3] found that support features are an important consideration for assisting users with learning how to use the system. The support features should be intuitive and include features such as automated frequently-asked questions and live help with customer support representatives.

\section{E-Payment Adoption}

In a review of literature [10] identified many of the factors behind the increased adoption of e-payments as a viable substitute for cash in all types of transactions. The review indicated that the stakeholders in e-payment systems often adopt a marketing perspective in which they design the system to meet the perceived needs of customers and communicate the benefits of the system to persuade users to conduct e-payment transactions. The majority of the research examining e-payments has been conducted in the banking industry in emerging economies. Consequently, there is some uncertainty as to whether the same factors influence epayment adoption in developed nations and in industries other than banking. The greatest barriers to the adoption of epayments among users was lack of knowledge and skills in how to use a specific e-payment system and the fear of a security breach that would lead to loss of funds or compromise of personal information.

[11] Conducted quantitative research to identify the factors influencing users to adopt online e-payment systems in the context of e-government. The model developed for the study proposed that past experience with the use of an e-payment system had a direct effect on perceived frictionless use, which is similar to ease of use. Past experience also has an effect on the degree of trust in the system, which is a function of the users' understanding of the security protocols used to provide user protections. Perceived frictionless use and trust are the two key variables affecting attitude towards the use of the epayment system. The findings showed that the characteristics of the users including education level and age have a significant influence on attitudes towards and intention to use e-payment systems.

Some research concerning e-payment adoption has focused on identifying the factors leading users to reject the use of any type or online e-payment system. [12] Conducted quantitative research to identify the most significant concerns of online banking and e-payment customers. The results showed that consumers balance the perception of financial and security risk with the anticipated benefit from using the e-payment system. In addition, the degree of perceived financial risk can be a deterrent to adopting e-payments with financial risk as the possibility of financial loss due to error. In addition, the degree of support to assist with the learning process necessary to use e-payments was an important factor influencing adoption. The findings of [10] provide support for the findings and conclusion drawn by [12] concerning the importance of ensuring the users of e-payment systems have enough knowledge and skills to use the technology.

\section{CONCEPTUAL FRAMEWORK}

The Unified Theory of Acceptance and Use of Technology (UTAUT) provided the conceptual framework for the study. [13] Developed UTAUT from an examination and synthesis of the existing technology acceptance models. Some of the underlying theories incorporated into UTAUT include the Theory of Planned Behavior, the Theory of Reasoned Action, and the Technology Acceptance Model [14]. A technology acceptance model is intended to provide the predictors leading an individual to develop a positive attitude towards a technology. The positive attitude is an antecedent variable to the actual use of the technology and therefore is a strong predictor that an individual will routinely employ the technology. The UTAUT model is generally applied to the intention to adopt a new computer technology such as the intention to use online payment systems among customers of banks. The UTAUT model has been empirically verified to be a valid predictive model for the adoption of a technology [15].

The UTAUT model contains the assumption that the variables of performance expectancy, effort expectancy, and social influence affect the intention to behave in a specific manner. If the necessary facilitating conditions exist, the individual will engage in the behavior of using the technology [16]. Performance expectancy is the degree to which an individual believes the use of the technology will achieve a goal [14]. Effort expectancy is the degree of perceived ease associated with using a technology [15]. Social influence is the degree that an individual believes that others recommend using the technology [14]. Numerous antecedent variables contribute to each of the three major variables of the UTAUT model. Moderating variables also affect the relationship of performance expectancy, effort expectancy, and social influence to the attitude towards the technology. Moderating variables include the personal characteristics of the individual such as age, gender, previous experience with similar types of technology, and the voluntariness of using a technology.

In the context of e-payments, perceived security is an antecedent variable affecting performance expectancy. When an individual uses on online e-payment system, there is an expectation that the transaction will remain private and secure from interception by unauthorized parties [17]. If the user does not perceive the e-payment system as secure, there user will be reluctant to use the system. Because the perception of security is subjective, the system has to have actual security protocols of which the user is aware. In addition, the user has to belief the security protocols in place meet the expectations of the user. Because most users are not specialist in the technology, they consider the statements of the system provider such as a bank as evidence of the security features of the e-payment system.

The perception of usability is an antecedent variable of effort expectancy when the UTAUT model is applied to e-payments. The user of the system has to perceive the operation of the epayment system is consistent with their existing technical knowledge and skills [18]. In addition, the user must believe the system can be instrumental in achieving an important goal such as making or receiving a payment with a minimal amount of effort or additional learning. The users of a system 
often form their perceptions of usability based on their actual experience with a system.

Social influence affects adoption of e-payment systems by creating the perception that use of the system is socially acceptable and desirable [6]. Factors such as the adoption of the technology by an individual's social network and the perception of the value of the technology become an important influence on attitudes. In addition, information about negative experiences with a technology can rapidly travel through a social network, fostering reluctance to use the technology. According to the previous discussion of the literature review the research model was proposed.

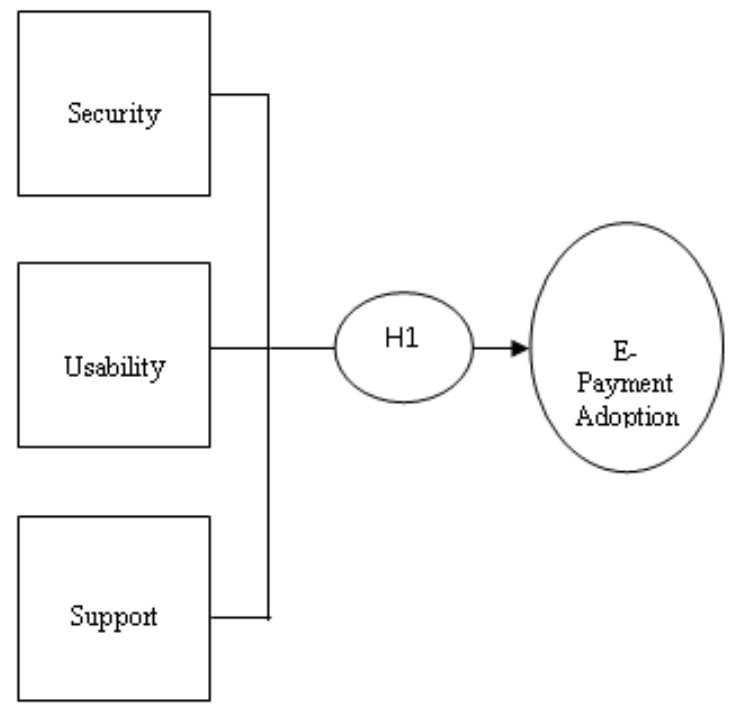

\section{MATERIALS AND METHODS}

A random sampling approach was used to collect data from employees and managers of banks offering customers epayment services. A random sampling approach is a form of probability sampling that is based on the assumption the population under investigation is heterogeneous and therefore data must be taken from a random group of people [19]. A large enough random sampling will produce data reflecting a normal curve with a standard error providing information about the way the data from the population is distributed around the mean.

The participants in the study were randomly selected from directories of the banking industry in Jordan. The survey questionnaire was disseminated to the study population via email with a note explaining the purpose of the research and the respondents' roles in filling out the questionnaire. The participants were given assurances of anonymity to encourage participation and candid answers. A total of 325 solicitations for participation were made with 256 completed questionnaires returned, which is a response rate of $78.7 \%$. The percentage of completed responses suggests that selfselection bias is not a significant factor influencing the findings of the study, which should be above 70\% [20].

\subsection{Instrument}

The data necessary to answer the research question were collected through the use of a survey questionnaire. The survey questionnaire was developed specifically for the study. The survey questionnaire consisted of two parts. The first part of the survey questionnaire collected demographic data about the respondents in the study, which is necessary to identify the characteristics of the sample population. The first part of the survey questionnaire asked about the age, gender, education and position of employment of the respondents. The first part of the survey questionnaire also contained pre-defined categories for the demographic variables, which facilitated coding and analysis.

The second part of the survey questionnaire contained 21 statements with the respondents required to select their level of agreement with the statement by indicating agreement on a 5-point Likert scale. The respondents were asked to rate their level of agreement with the statement ranging from strongly disagree to strongly agree. Limiting the scale to five points is generally considered to provide accurate reliability and sensitivity for the statements assessed in the scale [21]. The second part of the survey questionnaire had questions related to the four domains of security, usability, support, and epayment adoption.

\subsection{Reliability}

The reliability of the survey questionnaire was assessed using Cronbach's alpha. Cronbach's alpha is a measure of the internal consistency that is based on the correlations between each item of a measure and each of the other items on the test. The approach is based on the assumption that if all items in a scale are indeed measuring the same construct, a high degree of correlation should exist between the items in the scale. Cronbach's alpha will range from 0 to 1 , with a value of .7 considered sufficient to establish reliability for psychometric tests [22].

A separate reliability analysis was performed for the questions in each of the four domains of security, usability, support, and e-payment adoption. The analyses indicated that each of the domains had a Cronbach's alpha above .7 and are therefore have sufficient reliability. Table 1 shows the results of the reliability analysis

Table-1 Reliability Analysis

\begin{tabular}{|l|l|l|}
\hline Contract & $\begin{array}{l}\text { Alpha } \\
\text { Coefficient }\end{array}$ & $\begin{array}{l}\text { Number of } \\
\text { Item }\end{array}$ \\
\hline Security & .847 & 5 \\
\hline Usability & .813 & 6 \\
\hline Support & .778 & 5 \\
\hline E-Payment Adoption & .865 & 5 \\
\hline
\end{tabular}

\subsection{Demographic Profile of Respondents}

The analysis of the data provided by the respondents revealed the demographic profile of the sample population. The analysis showed the majority of respondents were males between the ages of 31 and 40, who held a bachelor's degree and held the position of employee. Table 2 contains the demographic variables, the percentages, and the cumulative percentages of the different demographic categories assessed in the survey questionnaire.

Table-2 Demographic Profile of the Respondents

\begin{tabular}{|l|l|l|}
\hline Variables & Percentages & Cumulative (\%) \\
\hline Gender & & \\
Fale & 66.2 & 82.8 \\
& 33.8 & 100.0 \\
\hline
\end{tabular}




\begin{tabular}{|l|l|l|}
\hline Age & 13.4 & 13.4 \\
30 or less & 54.2 & 67.6 \\
$41-40$ & 26.1 & 93.7 \\
Above 51 & 6.3 & 100.0 \\
& 100.0 & \\
\hline Education & 11.3 & 11.3 \\
Diploma & 84.9 & 96.2 \\
Bachelor & 3.8 & 100.0 \\
Post graduate degree & 100.0 & \\
\hline Position & & \\
General Manager & .8 & .8 \\
Deputy Manager & 1.7 & 2.5 \\
Manager & 13.0 & 15.5 \\
Employee & 84.5 & 100 \\
& 100 & \\
\hline
\end{tabular}

\section{RESULTS}

The results of the analysis of the data from the respondents provide support for accepting the alternative hypothesis examined in the study, which was: $\mathrm{H \alpha}$ : A statistically significant relationship exists between Security, Usability, and Support and E-Payment Adoption. The results show that the predictor variables of Security, Usability, and Support have a statistically significant relationship with the outcome variable of E-Payment Adoption.

The analysis also showed an F-value of 139.171 with a significance of 0.00 . In general, a larger F-value is associated with a better regression model. The level of significance of the $F$ value is 0.00 , which suggests that there is a statistically significant relationship between the set of three predictor variables and the outcome variable.

A regression analysis was performed on the data, which produced a coefficient of determination (R2) of .641 and an adjusted R2 of .636, with the adjusted R2 accounting for variables that may not have been considered in the model.

The adjusted R2 indicates that the three predictor variables of Security, Usability, and Support account for approximately $63.6 \%$ of the variation in the outcome variable of E-payment Adoption, with other variables not accounted for in the model also influencing E-Payment Adoption.

The value of the adjusted R2 suggested that the model in which Security, Usability, and Support exert influence on EPayment Adoption has moderate goodness of fit.

The analysis of the data also showed that each of the three variables are have a statistically significant $t$-value at a $p \leq$ .05 , with the predictor value of Security just at the acceptable level of statistical significance. The analysis also showed that the predictor variable of Support has the greatest influence on the outcome variable of E-Payment Adoption with a standardized coefficient $(\beta)$ of .526 . The results suggests that for every .526 change in the perceptions of Security among managers and employees of banking organizations, the perceived E-Payment Adoption increases by 1. Table 3 presents the $\beta$, the $\mathrm{t}$-value, and the significance of the three predictor variables of the study.

Table-3 Standardized Coefficients, T-value and Significance

\begin{tabular}{|c|c|c|c|}
\hline Model & $\begin{array}{l}\text { Standardized } \\
\text { Coefficient }(\beta)\end{array}$ & t-value & Sig. \\
\hline (Constant) & -- & 2.030 & .043 \\
\hline Security & .115 & 1.971 & .050 \\
\hline Usability & .220 & 2.784 & .006 \\
\hline Support & .526 & 7.751 & .000 \\
\hline
\end{tabular}

\section{DISCUSSION}

The results of the study show that the perception of Security, Usability, and Support are predictor variables for the outcome variable of E-Payment Adoption. The findings of the study provide support are consistent with the propositions of UTAUT in which Security, Usability, and Support are proxy measures for the constructs of performance expectancy, effort expectancy, and social influence respectively.

The findings are also consistent with previous research. The perspective of individuals in the banking industry is that users must perceive the e-payment system as secure before forming a positive attitude that leads to adoption [2]. The respondents also believed that users of an e-payment system must also believe they have the knowledge and skills to use the technology with the design of the system a critical element for adoption[3]. The findings of the study also determined that the perception of support was the most critical variable for EPayment Adoption, which is consistent with the findings of [9].

The results of the study suggest that banks and other organizations providing E-Payment capability to customers should focus on ensuring that the system is secure, usable, and has well-developed automated and live support capabilities. The three variables have substantial influence over the attitude to users towards an e-payment system. When individuals have a positive attitude, they are more likely to adopt an e-payment system.

\section{CONCLUSION}

The findings of the study support the conclusion that managers and employees of banks in Jordan believe the organization can develop a competitive advantage leading to greater use of their e-payment systems by devoting attention to improving security, usability, and support systems.

The findings also support the conclusion that managers and employees of banks believe the perceptions of the users of an e-payment system in critical areas such as safety and ease of use are important the positive attitude towards e-payments that is a necessary antecedent to actual use of e-payments. Consequently, banks in Jordan should focus on creating secure and easy-to-use platforms to facilitate e-payments and communicate the security and usability features to the potential users of the e-payment system. Establishing a support system may be the most critical aspect to foster epayment adoption by customers who believe they may require 
assistance in the event they develop problems using epayments offered by a banking institution

The findings are limited, however, because of the possibility that other variables not considered in the current research may have influenced the relationship between the predictor variables and the outcome variables. Further research should be conducted to determine the full range of variables affecting e-payment adoption in Jordan. In addition, future research should investigate the specific elements of security, usability, and support to facilitate e-payment adoption.

\section{REFERENCES}

[1]. Martins, C., Olivera, T., \& Popovic, A. (2014). Understanding internet banking adoption: A unified theory of acceptance and use of technology and perceived risk application. International Journal of Information Management, 24(1), 1-13.

[2]. Niranjanamurthy, N., Kavyashree, M., Jagannath, S., \& Chahar, D. (2013). Analysis of e-commerce and mcommerce: Advantages, limitations and security issues. International Journal of Advanced Research in Computer and Communication Engineering, 2(6), 2360-2370.

[3]. Barnard, Y., Bradley, M., Hodgson, F., \& Lloyd, A. (2013). Learning to use newer technologies by older adults: Perceived difficulties, experimentation behavior, and usability. Computers in Human Behavior, 29, 17151724.

[4]. Demodarian, L., \& Sandhu, J. (2016). The role of social context for ICT learning and support for reducing digital inequalities for older ICT users. International Journal of Learning Technology, 11(2), 156-175.

[5]. Urs, B. (2015). Security issues and solutions in e-payment systems. Fiat Iustitia, 1, 172-179.

[6]. Liebana-Cabanillas, F., Sanchez-Fernandez, J., \& MunozLeiva, F. (2014). Antecedents of the adoption of the new mobile payment systems: The moderating effect of age. Computers in Human Behavior, 35, 464-478.

[7]. Qteishat, M. (2014). The impact of information system success factors, human resource staff satisfaction, and ehuman resource use on organizational benefit. International Journal of Computer Applications, 105(2), $1-7$.

[8]. Chan-Olmstead, S., Cho, M., \& Lee, S. (2013). User perceptions of social media: A comparative study of perceived characteristics and user profiles of social media. Online Journal of Communications and Media Technologies, 3(4), 149-178.

[9]. Balasubramanian, S., Jagannathan, V., \& Natarajan, T. (2014). Information systems success in the context of internet banking: Scale development. Journal of Internet Banking and Commerce, 19(3), 1-15.
[10] Kabir, M., Saidin, S., \& Ahmi, A. (2015). Adoption of epayment systems: A review of literature. Proceedings of the International Conference on e-Commerce. Retrieved from:

https://www.researchgate.net/profile/Aidi_Ahmi/publicat ion/303329794_Adoption_of_ePayment_Systems_A_Re view_of_Literature/links/573d2cf808aea45ee841a78c.pd f.

[11]. Treiblmeyer, H., Pinterits, A., \& Floh, A. (2006). The adoption of public e-payment systems. Journal of eGovernment, 3(2), 33-51.

[12]. Lee, M. (2009). Factors influencing the adoption of internet banking: An integration of TAM and TPB with perceived risk and perceived benefit. Electronic Commerce Research and Applications, 8, 130-141.

[13]. Venkatesh, V., Morris, M., Davis, G., \& Davis, F. (2003), User acceptance of technology: Toward a unified view. MIS Quarterly, 27(3), 425-427.

[14]. Oh, J., \& Yoon, S. (2014). Predicting the use of online information services based on a modified UTAUT model. Behavior and Information Technology, 33(7), 716-729.

[15]. Abrahao, R., Moriguchi, S., \& Andrade, D. (2016). Intention of adoption of mobile payment: An analysis in light of the Unified Theory of Acceptance and Use of Technology (UTAUT). Review of Administration and Innovation, 13, 221-230.

[16]. Slade, E., Dwivedi, Y., Piercy, \& Williams, M. (2015). Modeling remote consumers' adoption intentions of remote mobile payments in the United Kingdom: Extending UTAUT with innovativeness, risk and trust. Psychology \& Marketing, 32(8), 860-873.

[17]. Abubakar, F., \& Ahmad, H. (2013). The moderating effect of technology awareness on the relationship between UTAUT and behavioral intention to use the technology: A conceptual paper. Australian Journal of Business and Management Research, 3(2), 14-23.

[18]. Hanafizadah, P., Keating, B., \& Khedmatgozar, H. (2013). A systematic review of internet banking adoption. Telematics and Informatics, 31(3), 492-510.

[19]. Babbie, E. (2016). The basics of social research. Boston MA: Cengage.

[20]. Fowler, F. (2009). Survey research methods. Thousand Oaks CA: Sage Publications.

[21] Leung, S. (2011). A comparison of psychometric properties and normality in 4, 5, 6 and 11 point Likert scales. Journal of Social Service Research, 37, 412-421.

[22]. Dewberry, C. (2004). Statistical methods for organizational research. New York NY: Routledge. 